\title{
DESIGN OF INDONESIAN NAVY PERSONAL EQUIPMENT MONITORING SYSTEM BASED ON ANDROID MODEL
}

\author{
Sunarta, Alexander Victor Bukit, Arie Marbandi, Kusdianto \\ D-3 Informatics Engineering, \\ Indonesian Naval Technology College, STTAL Surabaya Indonesia
}

\begin{abstract}
Kaporlap is individual equipment that is attached to the body of a soldier, including all accessories, ranging from headgear, body cover to leg cover. These individual equipment were distributed so that each soldier could carry out basic tasks or routine daily tasks and the additional tasks provided could run well. Design and Development of the Navy-based College of Technology Kaporlap Monitoring System (STTAL) Android-based is an information system designed to make it easier for Kaur warehouse to make a report to the Kadeprenalog to find out stock information available at Renalog warehouse when it will distribute Kaporlap to Personnel and Students. Data collection methods used in the preparation of this final project are field studies and literature. After being identified, the authors designed the Kaporlap inventory system with systems development models such as context diagrams, Data Flow Diagrams (DFD), Entity Relationship Diagrams (ERD) through to Input and Output designs, then proceed with the making of its web program and after that it can uploaded to the android system. After the whole system process is complete, it can be seen that the inventory system can produce information for official needs accurately and quickly.
\end{abstract}

Keywords : Kaporlap Inventory System, Web Data, Android Applications.

\section{INTRODUCTION}

\subsection{Background}

The Naval College of Technology or (STTAL) is the implementing unit of education at the Indonesian Navy Institute established since 1966. It is responsible for carrying out educational development program activities in the field of defense technology. The Naval College of Technology is an implementing and coaching element that is directly under the Commander of the STTAL. STTAL was established and has the main task of assisting the Chief of Staff of the Navy in carrying out the education provided for high schools in the field of science and technology (IPTEK) as well as fostering all levels of staff including facilities and infrastructure to support the organic Navy basic tasks.

Every soldier and student in STTAL is entitled to a Kaporlap. Kaporlap is the abbreviation for Personal and Field Equipment, the equipment starts from the headgear, uniforms, shoes and other complementary attributes in supporting the activities of the Soldier. Every personnel who is declared to have been selected in the Navy and who has entered service in the Navy will receive the individual and field equipment (Kaporlap). Especially for soldiers serving in STTAL will get the Kaporlap ration through the STTAL Budget and Logistics Plan (Renalog).

The current conditions in the STTAL Renalog in terms of the administration of recording incoming and outgoing goods as well as for knowing the stock list of Kaporlap goods in the warehouse are still done manually, namely by using Microsoft Excel so it requires a relatively long time. Besides the relatively long time it certainly can cause problems, namely the late distribution of Kaporlap to Soldiers and Students.

Based on the description above, Renalog really needs to have a Kaporlap monitoring system. The system is expected to improve the quality of services, especially in the field of data collection in Renalog warehouses, so that by making this application it is expected to facilitate Kadeprenalog to monitor incoming and outgoing Kaporlap and Kaporlap stock available in the Renalog warehouse. 


\subsection{Problem Formulation}

Based on the above problems, it can be formulated how to design and build a Kaporlap monitoring system using an Android-based application in Renalog STTAL can be formulated as follows:

a. How to make a better application than the previous system that still uses Microsoft Excel?

b. How to design an application to handle the process in collecting incoming and outgoing goods?

c. How to build a stock inventory monitoring system that can provide information quickly, precisely and accurately?

\subsection{Research Objectives}

So the purpose of the design of the Android-based Naval Technology College Kaporlap Monitoring System Design is:

a. To design a monitoring system for goods that is in accordance with the problems in the inventory inventory of goods in the STTAL Renalog.

b. To make it easy for Kaur warehouse to create a monitoring system that can control the stock of goods in the warehouse so that it can notify about the amount of Kaporlap stock in the warehouse quickly, precisely and accurately so that it can provide information as needed.

c. To make it easy for the Kadeprenalog to find out information about the stock of goods available in the Renalog warehouse when it is going to distribute the Kaporlap to existing Personnel and Students for reporting responsibilities to the STTAL Commander.

d. To find out the readiness of the Kaporlap in the warehouse (damaged / feasible goods) distributed.

\subsection{Research Benefits} follows:

The benefits of the research are as

a. Help the warehouse in the data collection process Kaporlap (goods in and goods out) so that it makes it easier for the Warehouse Kaur in providing information needed Kaporlap.

b. To support the performance of warehouses in avoiding data errors in the amount of inventory. c. Produce information that is fast, precise and accurate for its users.

\subsection{Limitation of Problems}

In solving the problem of this Monitoring System Plan, limitations are needed to overcome the problem with the aim of facilitating the planning process by emphasizing the subject for better. Limitation problems in this study are:

a. The system made consists of:

1) Incoming Kaporlap data

2) Kaporlap data out.

3) Goods stock data.

4) Returns / Conditions of Goods.

b. This monitoring system is only used in the STTAL work environment.

c. Not discussing Requests to Receive (PUT) goods and Requests to Hand Over (PUS) damaged goods in the Indonesian Navy.

\section{LITERATURE REVIEW}

\subsection{Monitoring System}

The system is a network consisting of procedures that are interrelated, arranged to carry out an activity or complete a particular goal expected. Monitoring can be interpreted as a cycle of an activity that includes the process of gathering, reviewing and reporting as well as actions on information obtained for the process being implemented. Generally, monitoring is used in checking between performance and predetermined targets. The system consists of interrelated elements, the elements that make up a system consists of:
a. Purpose, is the goal of the system
b. Limitation, is a limitation used in achieving the goals of a system.

c. Control, is supervision in the implementation for achieving the goals of a system.

d. Input, is part of the system that functions as the recipient of input data.

e. Process, is a part that functions to process data input into information to fit the needs of the recipient.

f. Output, is the result obtained from a system. 
g. Feedback, is a system that functions to see whether the system has run in accordance with the expected function.

\subsection{Kaporlap}

Understanding Kaporlap itself is everything related to personal equipment attached to the body of a soldier, including all accessories, ranging from headgear, body cover to leggings. These individual equipment were distributed, so that each soldier could carry out basic tasks or routine daily tasks and the additional tasks provided could run well. The following example of Kaporlap is in the following image:

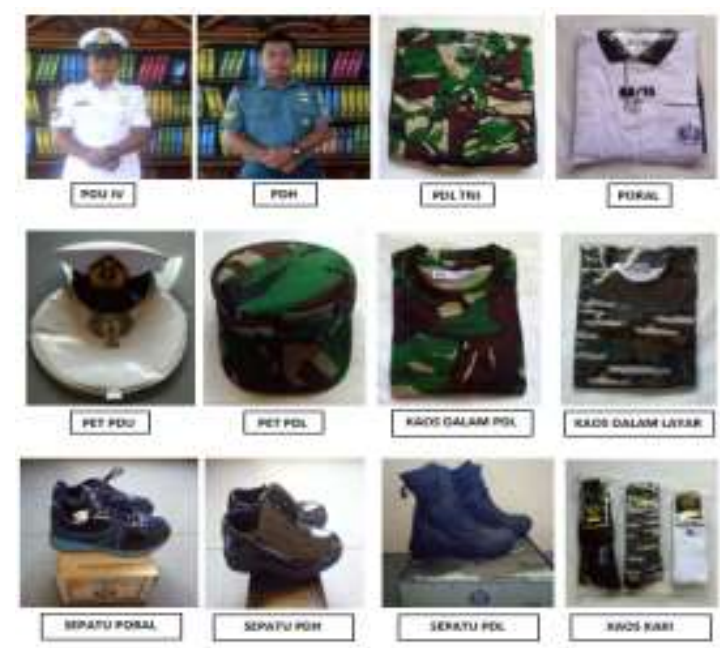

Figure 1 Navy Chief of Police

(Source: Author's Processed Results)

\subsection{PHP (Personal Home Page)}

According to Arief (2011c: 43), "PHP is a side-by-side server script that combines HTML to create dynamic website pages". Because PHP is server-side-scripting, the PHP syntax and commands will be run on the server and the results will be sent to the browser in HTML. Thus the program code written in PHP will not appear for users to make the security of web pages more secure. PHP is designed to create dynamic website pages, which are website pages that can create views based on new demands, such as displaying database content on web pages.

\subsection{Website}

A web page is a Hyper Text Markup Language (HTML) document format, which can always be accessed via HTTP, the protocol that sends information from the website server to be shared with users through a web browser. All publications from this website can form a large information network. Web pages are like books that can share information about various types of goods, advertisements and non-commercial. Through this web site that can provide specific information to others throughout the world.

\subsection{Bootstrap}

Bootstrap is a framework that can solve problems in web designing. The web appearance created by bootstrap will be resized to the screen of the browser used on desktop, tablet or mobile devices. This feature can be turned on or off with our own desires. So, we can create a desktop web display and when it is transferred by a mobile browser then our web display cannot change to the screen. With bootstrapping, we can also build dynamic or static webs.

\subsection{Android}

Android is one of the Operating Systems (OS) that is used for smartphones that are very popular today based on Linux. In addition to being popular, android has also captured the attention of many global mobile manufacturers. Currently, android has officially become part of the latest Operating System (OS) that is used for modern mobile devices such as smartphones and tablets. Since it was first released, Android has many versions. Various versions of andoid with all the features of their respective advantages. This is certainly in line with the Operating System (OS) of its longstanding competitors such as Apple IOS, Windows, Blackberry (BB), Symbian and others.

\subsection{Domain}

Domain is a unique name given to identify names on a computer server such as a web server or e-mail server on a computer network or a network on the internet. The domain name has a function to make it easier for users on the internet when going to access the server, besides that the domain is also used to remember the name of the server being visited without having to recognize a complex row of numbers known as IP addresses. This domain is also often known as a unit of a website such as: Wikipedia.org. Domain is also often referred to as URL, or website address.

\subsection{Hosting}

Web Hosting is a place or internet service that is used to store web files online so that they can be accessed by others. While hosting itself is a rental place to store data needed by the website so that it can be accessed by the internet which can be files, emails, images, applications and databases to 
display information on the internet in the form of HTTP, FTP, EMAIL or DNS. ( Hosting, nd)

\subsection{Barcodes}

Based on a computer dictionary and information technology, barcode means bar code, bar code or bar code. The codes that represent a certain information or data (usually the type and price of goods). Optical codes are in the form of vertical and black lines, beam bars that contain a different set of combinations and are sized and arranged. This code is printed on a sticker or pasted on the wrapper of an item (ii, 1997)

Basically, a barcode is an arrangement of black and white vertical lines of different thicknesses according to the contents of the code, a simple but useful optical code. With the use to store specific data.

\subsection{Barcode Reader}

Barcode reader is a tool that can read data on captured barcode and translate it into a data format that can be read by a computer. A barcode reader, also called a scanner, is a hand-held or stationary input device used to capture and read information contained in barcodes. The barcode reader consists of a scanner, a decoder connecting cable to the computer and a decoder. All three components must be installed in full so that the barcode reader can function and run as it should.

Interface device or called wedge, can be connected to a computer via a serial port, keyboard port. Data must be sent to a computer because the barcode reader is only for capturing and translating barcodes into numbers or letters, so that the software application can understand the data. The barcode reader works by directing light across the bar code and measuring the amount of light reflected back.

\section{RESEARCH METHOD \\ 3.1 Research Design}

This research aims to provide practical solutions to certain problems. The design is the taking of data of goods from one of the Navy's logistics warehouses that is integrated with the application program into an information system needed to support the operational activities of the Navy.

\subsection{Research procedures}

The research procedure is an explanation of the research process to be carried out, starting from the system design work diagram to the expected system input and output. Following is the overall research process in Figure 2.

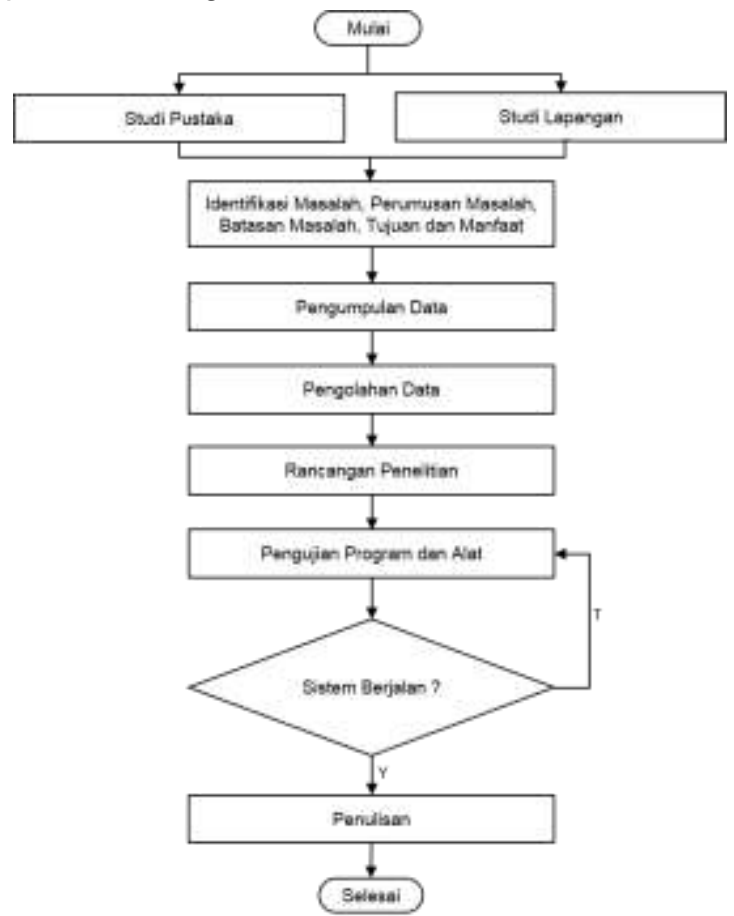

Figure 2 Research Flowchart

(Source: Author's Processed Results)

\subsubsection{Research Time and Place}

When the research in writing this final project began in July 2019 and is located at the STTAL Budget and Logistics Plan (Renalog) office located at Jl. Bumimoro Krembangan Surabaya.

\subsubsection{Research Tools and Materials}

In carrying out this research, several tools and materials are needed to facilitate the design and trial of research. The tools and materials needed in conducting the research include:
a. Laptop / Computer
b. XAMPP, Phpmyadmin
c. Browser Software
d. Domain and Hosting
e. Android phone
f. Barcode Reader 


\subsubsection{Research Design}

Research design can be interpreted as a process of analysis and collection of research data. In a broad sense, the design of this research includes the process of planning and conducting the research phase of studying the current system based on the results of a survey of existing problems. Furthermore, various survey results can be processed to get a general picture of the results obtained. General description of the STTAL Kaporlap Monitoring System in Figure 3.

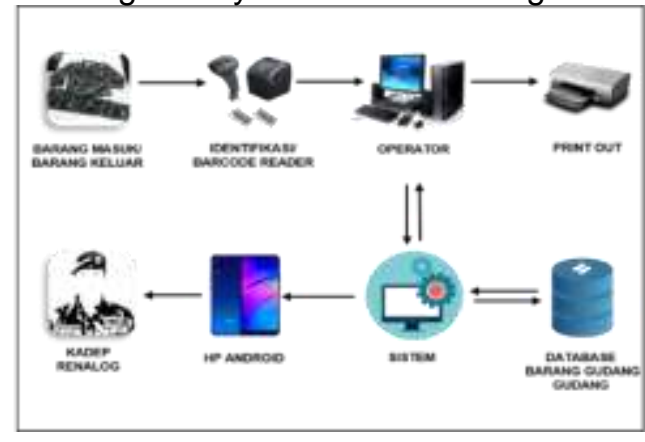

Figure 3 System Overview (Source: Processed Image Author)

\subsubsection{System Flow}

System flow is a system flow of the Android-Based STTAL Kaporlap Monitoring System. In the flow system that is in this information system is divided into the information system login process, the appearance of the application menu the process of calculating incoming Kaporlap, counting Kaporlap out, and calculating the remaining Kaporlap in the warehouse. Following is an example of the design of the STTAL Kaporlap Monitoring System Figure 4 in the form of a system flow.

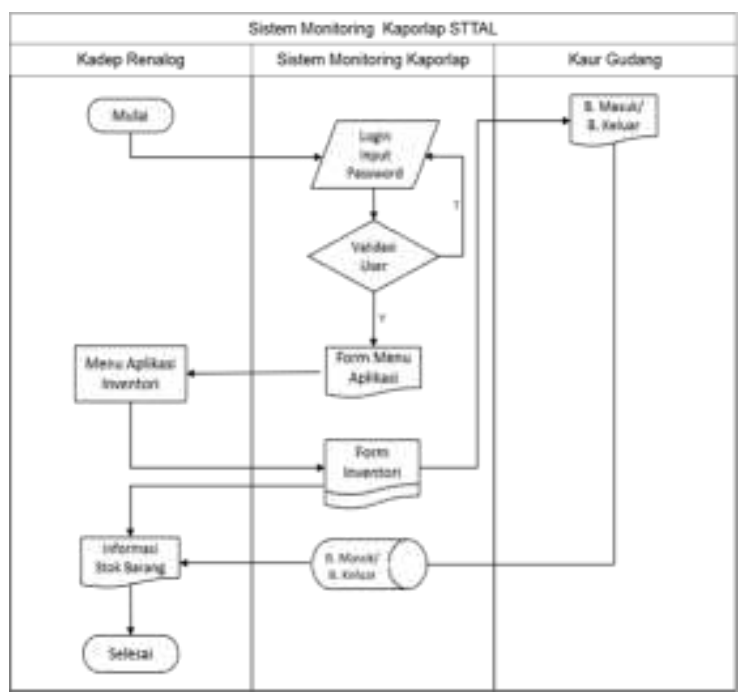

Figure 4 Data Processing Flow System (Source: Author's Processed Image)

\subsubsection{Entity Relationship Diagram (ERD)}

Entity Relationship Diagram (ERD) is a model for explaining relationships between data in a database based on data base objects that have relationships between relations. ERD is developed by using tables that are made according to needs.
a. Conceptual Data Model (CDM)
In database planning a program uses the conceptual data model (CDM) as a basic concept. In the planning of information systems contained in the STTAL Kaporlap Monitoring system using several related tables. Following is an example of the design of the STTAL kaporlap Monitoring system, Figure 5 in the form of Conceptual Data Mode (CDM).

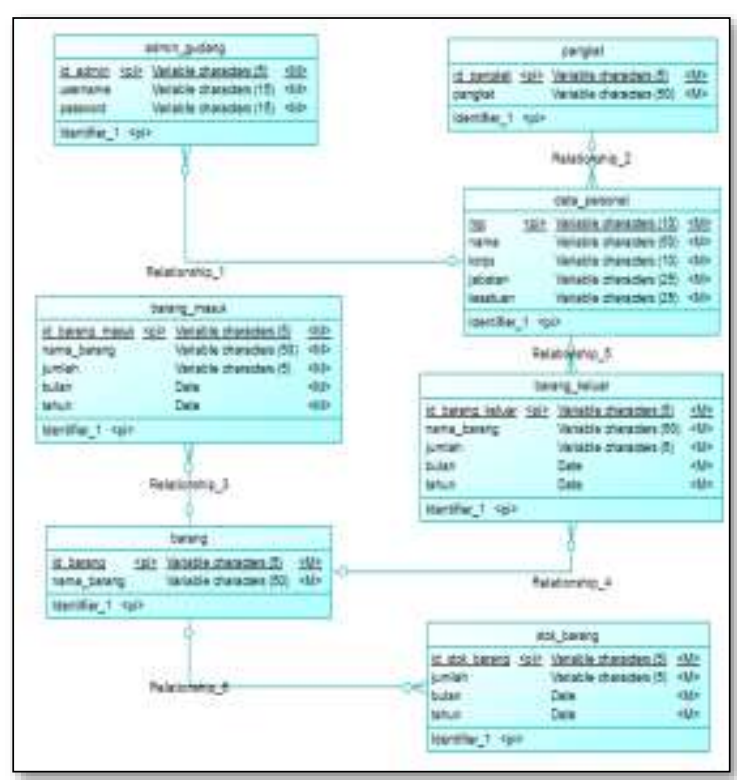

Figure 5 Conceptual Data Mode (CDM)

b. Physical Data Mode (PDM)

With the CDM generation in the STTAL Kaporlap Monitoring system, a Physical Data Model (PDM) is obtained which contains a table that is equipped with a table attribute. In this kaporlap iventori system has 5 tables including a table of members of the warehouse, personnel table, table of goods in, table of goods out and table of goods stock. Following is an example of the design of the STTAL kaporlap Monitoring system, Figure 6 in the form of Physical Data Mode (PDM). 


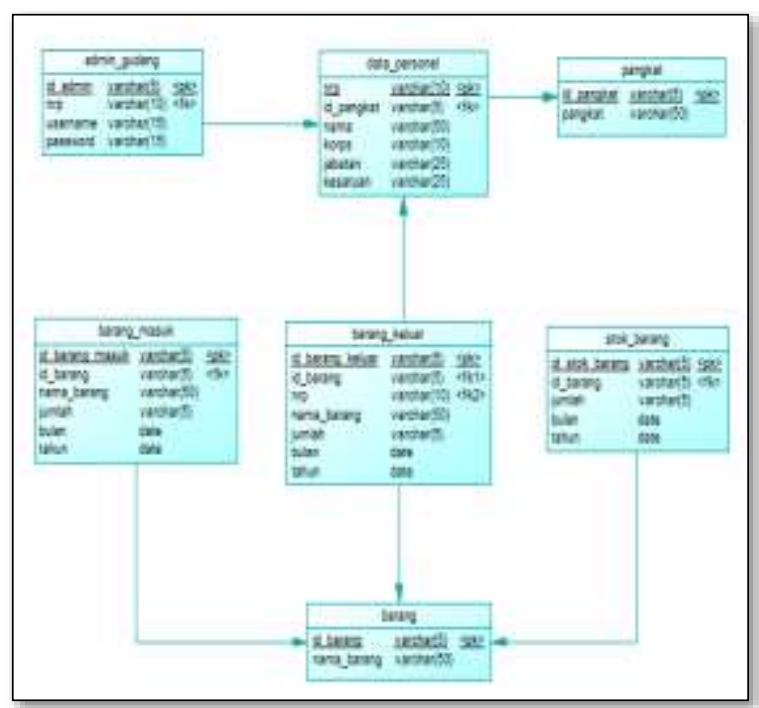

Figure 6 Physical Data Mode (PDM)

\subsubsection{Data Collection}

Data collection is a method of finding information and data needed in research so that it can present true and targeted information. In this study the authors conducted data collection using several methods.

\section{a. Observation Method}

Observation Method or observation is an activity carried out on an object with the intention of feeling and then understanding of a phenomenon based on knowledge and ideas that have been previously known, to obtain the information needed to continue research. Observation is also often interpreted as an activity of systematic observation and recording of symptoms that appear on research subjects.

\section{b. Interview Method}

Interview method is a method of data collection that is done by way of question and answer directly to the interviewees relating to the data needed in this study. The interview was held at the Naval College of Technology with the object of the student communication corps with the aim that the system to be built could function optimally in accordance with existing needs.

\subsubsection{Data Processing}

Data processing is the processing stage of the data that has been successfully collected obtained from the Renalog or Head of Warehouse in the form of data of kaporlap goods which are still in the form of an excel file.
Furthermore, the data is processed to be presented and applied in a system that is being studied by the author. Where data incoming and outgoing goods in the form of excel files will be imported into the Android-based Kaporlap monitoring system application. The system will be tried on the STTAL Renalog.

The main purpose of this application trial is to find out whether the application that has been made is able to meet the needs of the user and whether the application has been able to provide the results as expected. The trial is done by evaluating and experimenting on functions contained in the system. When an error is found, repairs will be made and then an evaluation and trial is carried out until the application does not experience an error.

\subsubsection{Operational Definitions}

Operational Definition is the determination of various definitions that will be used by the author in research. Operational definitions make abstract concepts an operational measure that makes it easier to measure variables. An operational definition can also be used as a definition limit that is used as a guideline for conducting an activity or research work.

\section{ANALYSIS AND DISCUSSION}

\subsection{Analysis of Data and Research Results}

Data analysis is an effort or a way to process data into information, so that the characteristics of the data can be understood and useful for the solution of problems, especially problems related to the research process or other definitions of data analysis, namely activities undertaken to convert data from research into information is expected to be used to draw conclusions. The expected goal of data analysis is to describe it so that the data can be understood and understood, then to make a conclusion or draw conclusions about population characteristics based on data obtained from the sample, this analysis is based on hypothesis testing.

The research results are a review of the validity of the research results. The discussion of the results of the study can be termed the original thought of the researcher to provide an explanation and interpretation of the results of the research that have been analyzed to answer the research questions. In essence, the discussion of research results is a discussion of the findings obtained. 


\subsubsection{System Analysis}

System analysis is an explanation and description of a complete information system into various component parts with the aim of being able to identify and evaluate all kinds of problems and obstacles that arise in the system so that later action can be taken to overcome, improve and develop. Analysis of a system that is running needs to be done so that the design of a proposed system has a clear source and makes it easier for writers to design the system to be proposed.

a. The following are the objectives of system analysis:

1. The main purpose of system analysis is to make a decision, if the system is problematic or cannot function properly and the results of the analysis can be used as a basis for improving the system.

2. Used to find out the scope of work to be carried out.

3. Identifying problems and looking for solutions to problems.

4. To study the current system.

b. Analyst System Function

1. Can identify problems from the user and admin.

2. To determine accurately the objectives that must be obtained in order to meet the needs of the user.

3. Can plan and implement a system design in accordance with what is desired by users.

\subsubsection{Use Case Diagrams}

Use Case Diagrams describe an interaction between the actor and the information system created. Following is the use case diagram of the system in the Inventory application as shown in Figure 7.

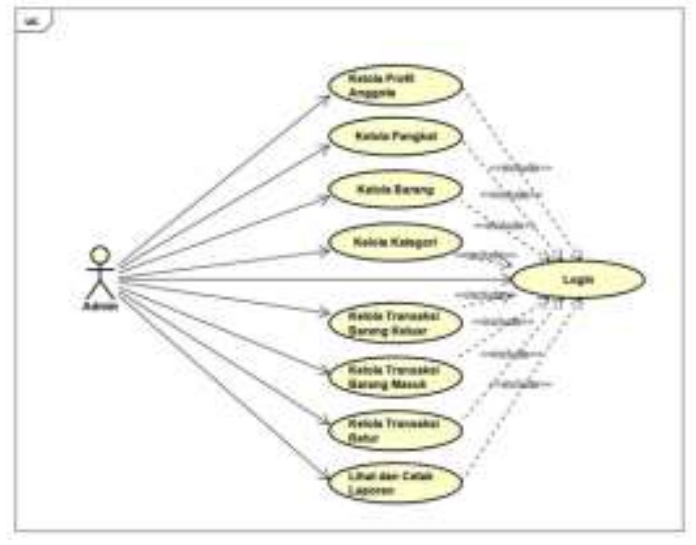

Figure 7 Use Case Diagrams Monitoring Application
In Figure 7, it can be seen that the Inventory application has 1 (one) actor, which is the admin. Admin actor can perform activity rights after logging in namely managing member profiles, managing rank data, managing item data, managing category data. Streotype <<include>> is used because all access can be done by the admin after logging in first. In addition to managing master data, admins can manage outbound goods transactions, incoming goods transactions, and return transactions. Admin actors can also view and print existing reports.

\subsubsection{Activity Diagram}

Activity Diagram illustrates the activities that occur in a process in the system. Here are some activity diagrams that exist in the Inventory application:

\section{a. Activity Login diagram}

The login process is an initial step before using the application. Admin access the website first. Admin enters username and password, the system will validate the login, if the username and password entered is invalid, the system will return the admin to the login page and display a message can not access. Valid data can open home page access. The login activity diagram process can be seen in Figure 8.

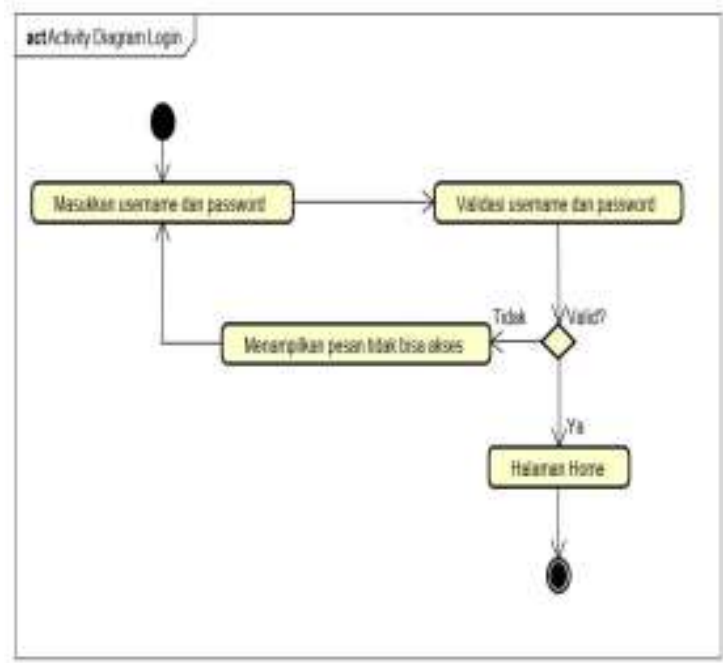

Figure 8 Activity Login diagram

b. Activity Diagram Print Stock Report In the stock diagram print activity diagram, the admin selects the stock report page. If the admin wants to print a report on certain items, he must find the item first. Then the admin can print 
the report. Activity diagram print stock reports can be seen in Figure 9.

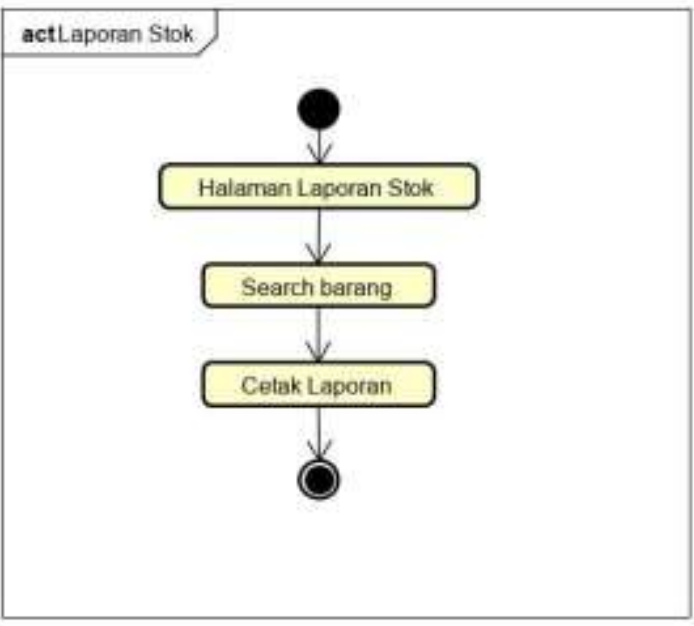

Figure 9 Activity Diagram Print Stock Report

\subsubsection{Sequence Diagram}

Sequence Diagram illustrates the interaction between objects in and around the system that shows step by step what should happen to produce something in the usecase. The following is a sequence diagram contained in the Inventory application:

a. Login Sequence Diagram

In the Login Sequence Diagram, the admin inputs the username and password after clicking the login button. The message will be forwarded by controllogin to validate whether it is registered in the database. The database will check the username and password. If the user is valid, the system will display a home page. Login Sequence Diagram can be seen in Figure 10.

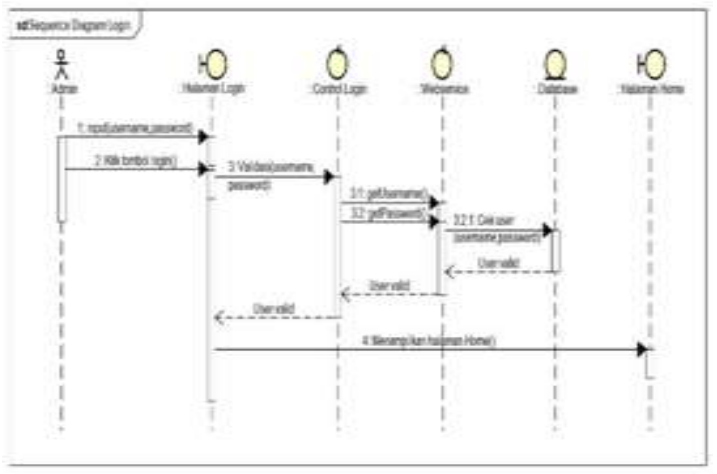

Figure 10 Login Sequence Diagram

b. Stock Report Sequence Diagram In the Stock Report Sequence Diagram, the admin accesses the stock report page and then looks for the item that you want to print. The system will automatically display a list of items according to item search. After that the admin clicks on the print button. The system will process the print and continue until it displays a stock report to be printed by the printer. The Stock Report Sequence Diagram can be seen in Figure 11.

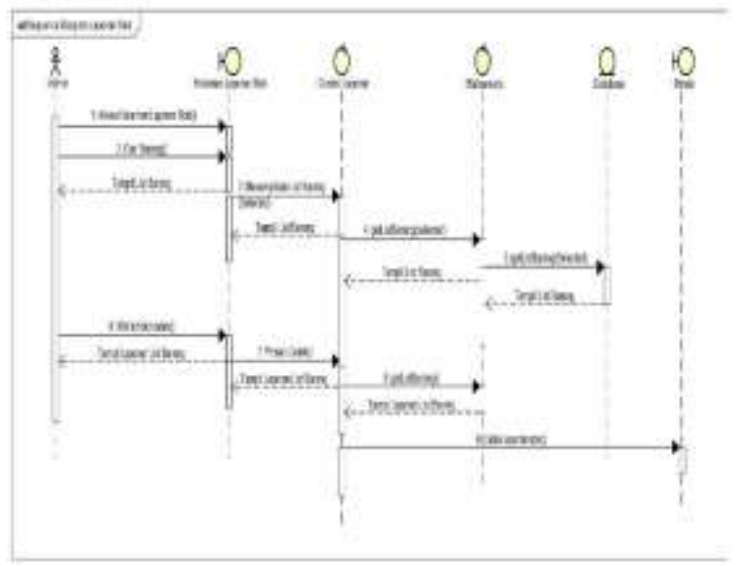

Figure 11 Sequence Diagram Stock Report

\subsection{Design}

The design is an initial process carried out to complete a project that will be done. A good analysis will make it easier to complete the project so as to produce a system that configures hardware and software so that it can solve the problem maximally. On the Android-Based Naval College High Technology (STTAL) Monitoring System the function is to find out the number of incoming and outgoing items and to provide stock information in the form of readiness of the condition of goods in the Renalog STTAL warehouse within a certain period of time. In this Kaporlap Inventory System design consists of several designs, namely input / output design, and form design.

\subsubsection{Input / Output Design}

Input / output design is a design in the STTAL Kaporlap Monitoring system, as a whole consisting of input and output designs. The explanation and appearance of each design will be discussed in the explanation of each design.

\section{a. Input Design}

Input design is a system application design that functions as admin (input) of Navy Navy's Kaporlap data in the Android-based Naval College of Technology (STTAL) Kaporlap Monitoring System. The overall input design consists of a login form in accordance with access rights, home form, master form and transaction form. 


\section{b. Output Design.}

Output design is a system application design that functions as a user or user who receives input from the admin in the NavyBased Technology College Kaporlap Monitoring System (STTAL). The overall output design consists of a login form in accordance with the access rights, Report Form within a certain period.

\subsection{Implementation}

The implementation is the result of the implementation of the research design and design of the Android-Based Naval College High Technology (STTAL) Kaporlap Monitoring System. This stage is a series of making applications that are tailored to the research design and system design that has been made and is ready to be implemented.

\section{a. Software}

The software needed is an Android computer and smartphone program and to operate the functions of this information system. The software required in the design and manufacture of an Android-based Naval College of Technology (STTAL) Kaporlap Inventory System is:

1) Windows operating system

2) Android operating system

3) UC Browser Browser

4) Domain and Hosting

5) MySql Database

b. System Implementation

The use of the program can be carried out after all software components that support the application process of the Android-Based Naval High School Technology (STTAL) Kaporlap Monitoring System. If the usage process is carried out correctly, the system is expected to be run to find out the number of Kaporlap in and the number of Kaporlap out and provide information on Kaporlap stock in the form of readiness of goods in the STTAL Renalog warehouse.

\section{1) Admin Login Form}

Login form is a form intended for users who have access to enter the system. Not everyone can log in, because only certain parties have access in the form of a username and password. In the information system that is built, the login is only for the admin because the admin can access the entire system starting from inputting, editing, deleting and storing data that is in the system. Login form can be seen in Figure 12.

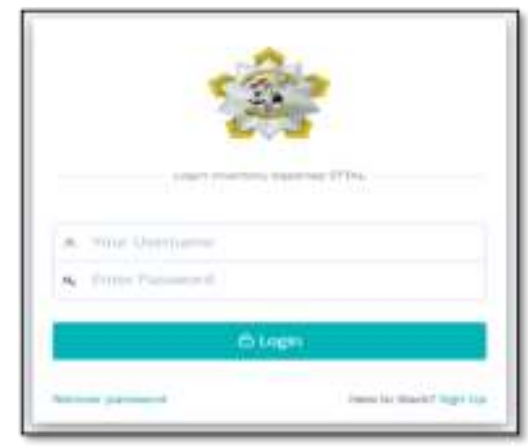

Gambar 12 Form Login Admin

\section{2) User Menu Form}

User Menu Design is the initial appearance after opening an inventory application. In the user menu design there is a menu option to report activities of incoming goods transactions, outgoing goods transactions, item returns, total stock of goods, profiles and exit menus to exit the application. The user menu dashboard design can be seen in Figure 13.

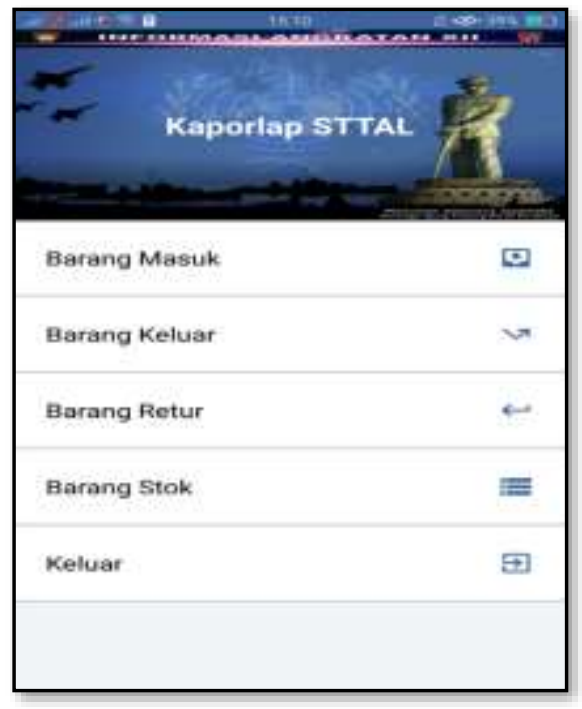

Figure 13 User Menu Form Design 


\subsection{Research Discussion}

The discussion conducted by the researcher is to provide an explanation and interpretation of the results of the research that has been carried out in order to conclude from the results of the discussion that has been carried out by the research. This contains the researcher's ideas related to what has been done and what was observed, presented and analyzed in the previous chapter. The description of this idea is related to theoretical results and other relevant study results. This thesis is complemented by research implications.

\subsection{Testing}

The purpose of testing the Naval High School Technology College (STTAL) Monitoring Kaporlap Based on Android is to determine the ability of several processes carried out in the system that has been built. System testing is performed on software and to determine the results of the design made.

\section{a. Software Testing}

Software testing is carried out to determine the extent of the work of the Kaporlap Inventory information system application program on android mobile phones. to find out the amount of goods entering, goods leaving, returns and stock of goods in the warehouse. Software testing is performed on this system, namely the display of incoming goods, display of goods out, display returns and display of goods as well as the logout process. Testing of the system can be seen in table 1 Testing admin software and in table 2 Testing user software.
Wesite Admin Software Testing

Table 1 Testing Website Software

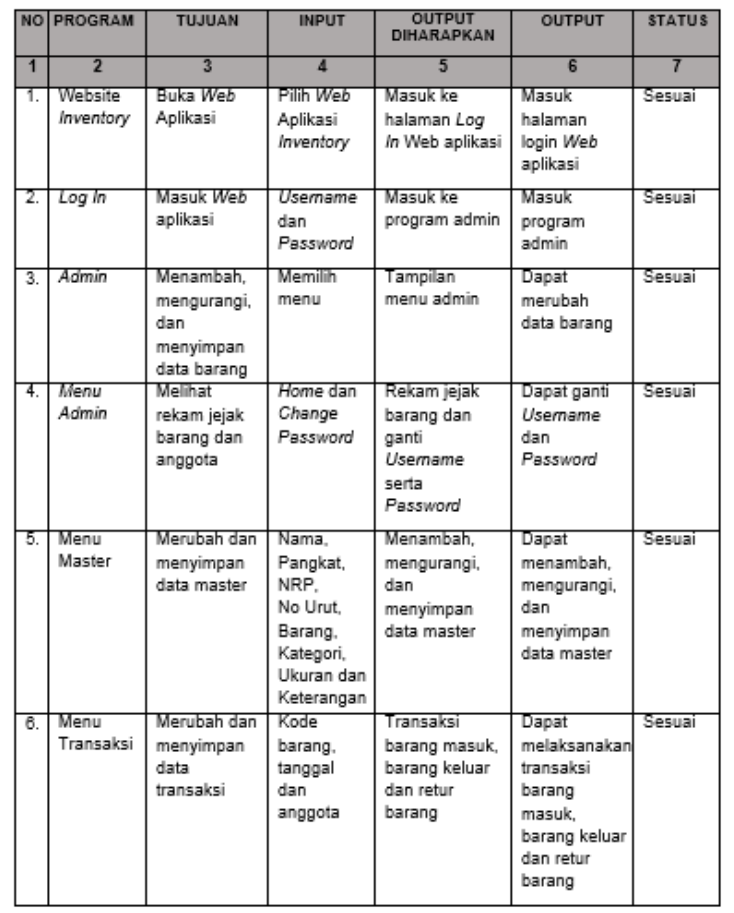

\section{User Software Testing}

Table 2 Testing User Software

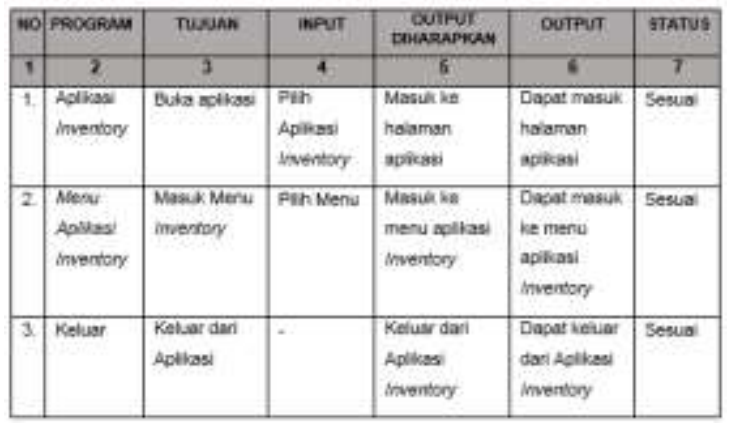

4.6 Results and Discussion

\section{a. Results}

Research on the design of the Android-based Naval College High Technology Kaporlap Monitoring System (STTAL) was carried out with overall system testing. The results were obtained based on testing conducted on the kaporlap inventory information application program system are:

1) Simplify the recording of incoming and outgoing goods.

2) Can see the track record of members who have taken goods. 
3) Can make it easier to see the remaining stock in the warehouse.

4) Can find out the condition of the readiness of goods in the warehouse (damaged feasible goods) distributed

\section{b. Discussion}

Research on the design of the Android-based Naval College High Technology Kaporlap Monitoring System (STTAL) is a type of applied research because this research aims to provide solutions and focus more on the application in the daily service of servicemen and when soldiers are on daily duty. This research can help the Kadeprenalog task in monitoring the amount of stock of goods in the warehouse before distribution to STTAL Personnel and Students, so as to obtain effective, efficient, accurate and real time results.

\section{CONCLUSIONS AND RECOMENDATION}

\subsection{Conclusions}

Based on the results of tests that have been carried out on the design of the NavyBased Technology College Headquarters Monitoring System (STTAL), the following conclusions are obtained:

a. Can input, edit and delete Navy personnel data in the STTAL work area.

b. Can provide information on incoming goods, exiting goods, returning goods and stock warehouse goods at any time without waiting for the results of the print.

c. Can display Navy Navy soldier's kaporlap data in the STTAL working area through the android application.

d. Can be used as a source for supporting monthly report generation.

\subsection{Recomendation}

From the results that have been made when designing and building the AndroidBased Naval College High Technology Kaporlap Monitoring System (STTAL) so that it can be used as suggestions:

a. In order to add a notification system notification on the application when there is a change in warehouse data data in the android application. b. In order to add to the process of Request to Receive (PUT) goods for personnel and students as well as Request to Submit (PUS) damaged goods in the warehouse.

\section{ACKNOWLEDGEMENT}

The authors greatly acknowledge the support from STTAL Surabaya Indonesia for providing the necessary resources to carry out this research work. The authors are also grateful to the anonymous reviewers and journal editorial board for their many insightful comments, which have significantly improved this article.

\section{REFERENCES}

Hosting, B.A.B. (N.D.). Hosting And Domains, 7-17.

Jogiyanto, H. (2005). Analysis \& Design Of Information Systems: A Structured Approach To The Theory And Practice Of Business Applications. Yogyakarta: Andi Offset.

Muhyuzir T.D., 2001, Analysis Of Data Processing System Design, Second Printing, PT. Elex Media Komputindo, Jakarta

Sidharta, L. (1995). Introduction To Business Information Systems. Jakarta: PT ELEX Media Komputindo.

JAYA, Iksan Et Al. DESIGN AND DEVELOPMENT OF EARLY HEAT STROKE DETECTION SYSTEM IN MILITARY CROSS COUNTRY BASED ON lot. INTERNATIONAL JOURNAL OF ASRO - STTAL, [S.L.], V. 9, N. 2, P. 141-151, Dec. 2018. ISSN 2460-7037. Available At: <Http://AsrojournalSttal.Ac.Id/Index.Php/ASRO/Article/Vi ew/241>. Date Accessed: 07 Apr. 2020.

HUDA, Khairul Et AI. INDONESIAN WARSHIP HISTORY INFORMATION SYSTEM OF INDONESIAN FLEET BASED ON WEB. INTERNATIONAL JOURNAL OF ASRO - STTAL, [S.L.], V. 10, N. 2, P. 105-115, July 2019. ISSN 24607037. Available At: <Http://AsrojournalSttal.Ac.Id/Index.Php/ASRO/Article/Vi ew/236>. Date Accessed: 07 Apr. 2020. 
FATURROCHMAN, Mochammad Et Al. DESIGN OF FUEL'S VOLUME MEASUREMENT MONITORING SYSTEM ON INDONESIAN NAVY FUEL TANK "SPBT" BASED ON THE Internet Of Things (lot). INTERNATIONAL JOURNAL OF ASRO - STTAL, [S.L.], V. 10, N. 1, P. 112-116, May 2019. ISSN 2460-7037. Available At: <Http://AsrojournalSttal.Ac.Id/Index.Php/ASRO/Article/Vi ew/235>. Date Accessed: 07 Apr. 2020.

WIBISONO, Bayu Et Al. DESIGN AND DEVELOPMENT OF MORSE LEARNING SYSTEM APPLICATION BASED ON VISUAL BASIC. INTERNATIONAL JOURNAL OF ASRO - STTAL, [S.L.], V. 10, N. 1, P. 105-111, May 2019. ISSN 2460-7037. Available At: <Http://AsrojournalSttal.Ac.Id/Index.Php/ASRO/Article/Vi ew/234>. Date Accessed: 07 Apr. 2020.

CANDRA, Depilia Surya; SYAHLAN, Zaenal; WIDODO, Edy. DESIGN AND DEVELOPMENT OF THE MEASURING OF THE BODY MASS INDEX TO THE INDONESIA NAVY BASED ON VISUAL STUDIO. INTERNATIONAL JOURNAL OF ASRO - STTAL, [S.L.], V. 10, N. 2, P. 116-124, July 2019. ISSN 2460-7037. Available At: <Http://AsrojournalSttal.Ac.Id/Index.Php/ASRO/Article/Vi ew/237>. Date Accessed: 07 Apr. 2020. 